This item was submitted to Loughborough's Research Repository by the author.

Items in Figshare are protected by copyright, with all rights reserved, unless otherwise indicated.

\title{
Equivocal invitations (in English)
}

PLEASE CITE THE PUBLISHED VERSION

https://doi.org/10.1016/j.pragma.2017.07.005

\section{PUBLISHER}

(c) Crown copyright. Published by Elsevier

\section{VERSION}

AM (Accepted Manuscript)

\section{PUBLISHER STATEMENT}

This work is made available according to the conditions of the Creative Commons Attribution-NonCommercialNoDerivatives 4.0 International (CC BY-NC-ND 4.0) licence. Full details of this licence are available at: https://creativecommons.org/licenses/by-nc-nd/4.0/

\section{LICENCE}

CC BY-NC-ND 4.0

\section{REPOSITORY RECORD}

Drew, Paul. 2019. “Equivocal Invitations (in English)”. figshare. https://hdl.handle.net/2134/25939. 


\title{
Equivocal invitations (in English)
}

\author{
Paul Drew \\ Loughborough University, UK \\ p.drew@lboro.ac.uk
}

February 2017

Forthcoming in a special issue of the Journal of Pragmatics on Invitations and responses: the formation of actions across languages, edited by Piera Margutti, Liisa Tainio, Paul Drew and Véronique Traverso

\section{$\underline{\text { Introduction }}$}

There has in recent years been a growing interest in the design and linguistic form, especially the grammatical form, of a range of actions conducted through talk, that are commonly regarded as initial actions (Couper-Kuhlen 2014). The caveat conveyed in 'commonly regarded as' requires some explanation; although we can usually identify a turn in which one speaker makes an offer to another, or requests another to do or give her something, apologises to or invites the other, it is rarely the case that these are 'firsts' in any clear sense; such actions can frequently emerge out of preceding talk, in which the movement or management towards the 'initial' action can be traced, so that the request or invitation is produced some way down a sequential line. Pre-sequences are perhaps the most familiar kind of sequential preludes to some 'initial' actions, but it is very frequently the case that such actions do not occur simply 'out of the blue' without any sequential preparation or prelude. Nevertheless, it is generally possible to identify the particular turn(s) in which one person makes an offer, makes a request, or apologises; as it is in this excerpt, which has been preceded by some extensive preliminaries (not shown) by Leslie before she makes her offer. 
Ex.1 [Holt:2:3] (Mary's husband has been made redundant; Leslie is offering to put him in touch with something like an agency her husband knows of, who may be able to help)

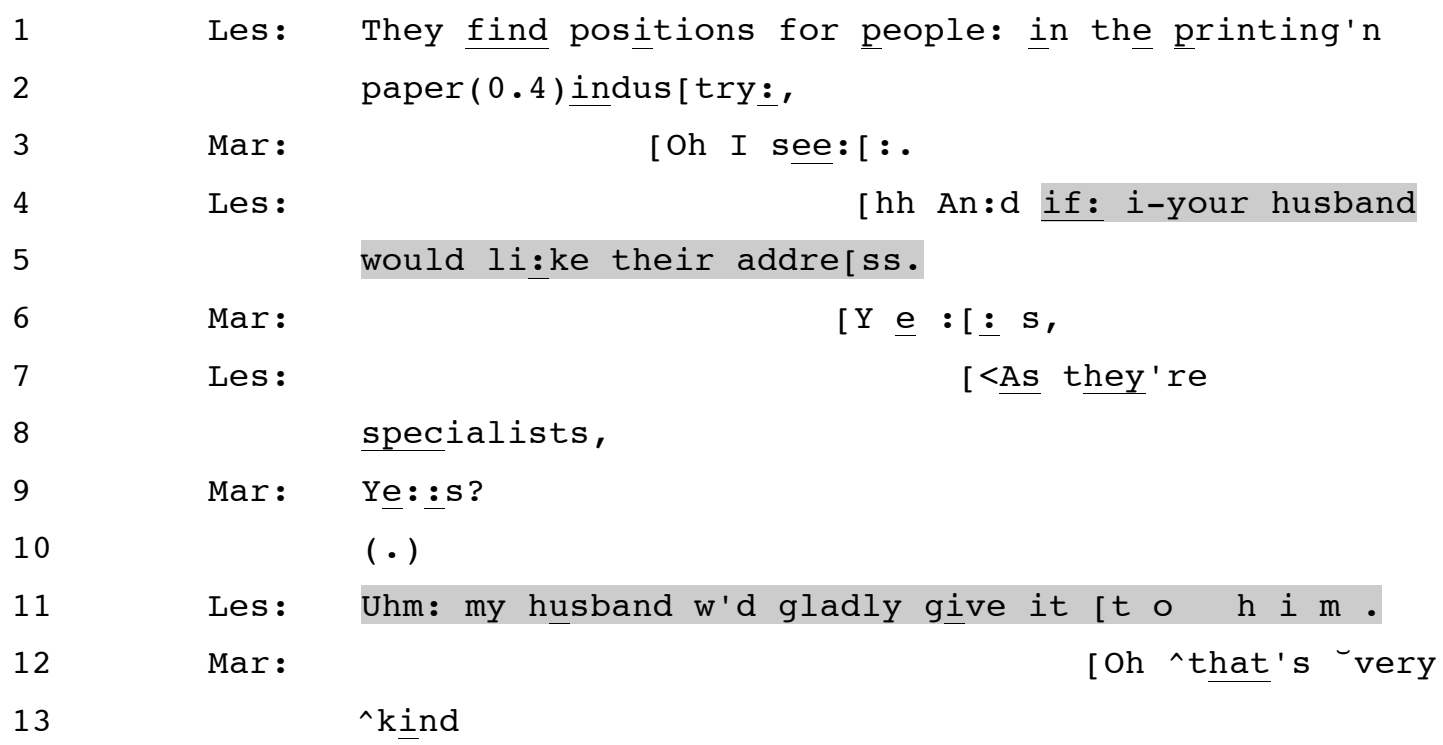

This offer is made through a particular (conditional) syntactic form, particular insofar as this form is used systematically when one participant has contacted the other in order to make an offer; when an offer is made in different sequential circumstances or environments, such as in response to the other having reported some trouble of difficulty, then a different form is used (Curl 2006). Much of the recent research into actions conducted in talk has adopted this approach of investigating the linguistic/syntactic form or design of the turn in which an action is conducted. Close analysis of that design may also reveal or enable us to discover who is being expected to carry out the intended action (agent), and who will benefit from the action (benefactive). That line of enquiry is making a valuable contribution to showing how participants distinguish between such actions as proposals, offers, requests or suggestions - that is, to distinguish between directives and commissives (CouperKuhlen 2014). Another approach is illustrated in research that demonstrates that the number of linguistic components, whether lexical or grammatical, with which a speaker constructs an apology manifests the speaker's treatment of the offence for which the apology is made as being less or more serious; a brief apology, often Sorry, treats the (virtual) offence as minor, as minimal, whereas expanded forms of apology treat the offence as more significant, partly through the inclusion of an overt expression of agency (I'm sorry), and through expansions to cover [agentive apology] $+[$ naming offence $]+[$ account (Heritage \& Raymond 2015). However, currently the 
principal analytic approach has been to explore the associations between linguistic form in turn design (Drew 2013a) and the specific sequential and interactional environments in which different forms are used (e.g. Curl \& Drew 2008).

Invitations are, like offers, actions that can inhabit a specific turn at talk and are done through distinctive and varying linguistic forms and turn design, illustrated in the following.

Ex.2 [TC1(a):14:2-5]

Alb: Uhhhhhh. So you guys coming over toni:ght?

\section{Ex.3 [NB:VII $]$}

Edn: $\quad$ hhhhh Wul why don't we: uh-m:=Why don't I take you'n Mo:m up there tuh: $\underline{\text { Coco's.someday fer lu}: n c h . ~}$

\section{Ex.4 [NB:II:2]}

Emm: Wanna c'm do:wn 'av a bi:te'a lu:nch with me?

Ex.5 [Kamunsky:3:2]

Alan: Uh nex'Saturday night's a s'prize party here fer p-Kevin. (0.2) p p! Egnd if you c'n make it.

Ex.6

Gor: .t.hhhhhh S:o:- (.) if you:'re (.) not doing anything .hhhhhh u (0.2) d-uh::m: some time one weeke:nd?

Ex.7 [Holt:X(C):2:1:2]

Les: $\quad \underline{\mathrm{O}} \underline{\mathrm{h}}::$. Well come over- 'n have a drị:nk'n a mince: pie:.

Ex.8 [JGII(b):8:14]

John: So in other words you'd go out if I:: askedche out one a' these times.

Each of these invitations is delivered through a particular turn design and linguistic construction, a So-prefaced contracted interrogative (ex.2); a Why don't we. . . construction (ex.3) (Couper-Kuhlen 2014, Drew 2013); a contracted form of Do you want to . . (ex.4); a conditional form (ex.5); a combination of So-prefaced and conditional forms (ex.6); a Well-prefaced directive (ex.7) (Heritage 2015); and a Soprefaced declarative form (ex.8). 
The variation in the forms through which these invitations are delivered is associated, broadly speaking, with two intersecting contingencies; the sequential and interactional circumstances (environment) in which the invitation is being made, and the kind of occasion that is represented in the invitation. The ways in which the design form(at) of an invitation is shaped by its interactional environment and represents a particular 'kind of occasion' will be explored in the next section. However, there is something further that, across the variation in their specific lexico-grammatical design, these designs have in common; and this is what I will demonstrate in this paper - that they are all equivocal forms of invitations. I mean by equivocal something like, not being sure, an uncertainty, a tentativeness in asking, amounting to a kind of cautiousness. This is not at all to imply anything like what Issacs and Clark (1990) claim for 'ostensible invitations,' invitations that, according to their analysis, are only pretence, done for form's sake, and are "non-serious speech acts" (Issacs and Clark 1990: 506-508). Issacs and Clark are interested in, and claim to be able to discern, the sincerity with which an invitation is made; they regard the form of ostensible invitations as embodying a pretence of sincerity, suggesting that a speaker may make the pretence "obvious enough that the addressee will recognize that it was intended to be seen as obvious" (Issacs and Clark 1990: 498). What I am describing as 'equivocal' constructions has nothing to do with the sincerity that might be imputed to an invitation, nor to pretence, nor to whether the speaker might prefer the recipient not to accept the invitation.

I am focusing instead on the cautiousness, the equivocation, that is evident in the details of the design of almost all the invitations (there is one exception, discussed towards the end) in my collection of over 30 invitations found in a data base of US and British English telephone calls (one that is widely available to and used by researchers in Conversation Analysis). My method of analysis here, CA, is founded on the interconnections between Action, Turn design and Sequence (Drew 2013a). In the analysis that follows I focus first of the ways in which the design of invitations reflects the interactional environment in which they are made, and second on the nature of the occasion to which the recipient is being invited. I then specify, third, those characteristics of the design of invitations that are associated with equivocation. 
The sequential environment in which invitations are made

A quite basic distinction can be made between invitations that are delivered as something like announcing the invitation as being the reason for calling (or calling by, in face-to-face interactions), and those that are locally occasioned sequentially by some preceding talk; this is to adapt somewhat Sacks's distinctions between announcements, touched off and occasioned talk (Sacks 1991. This is a familiar enough distinction, but perhaps should be explicated for invitations, specifically.

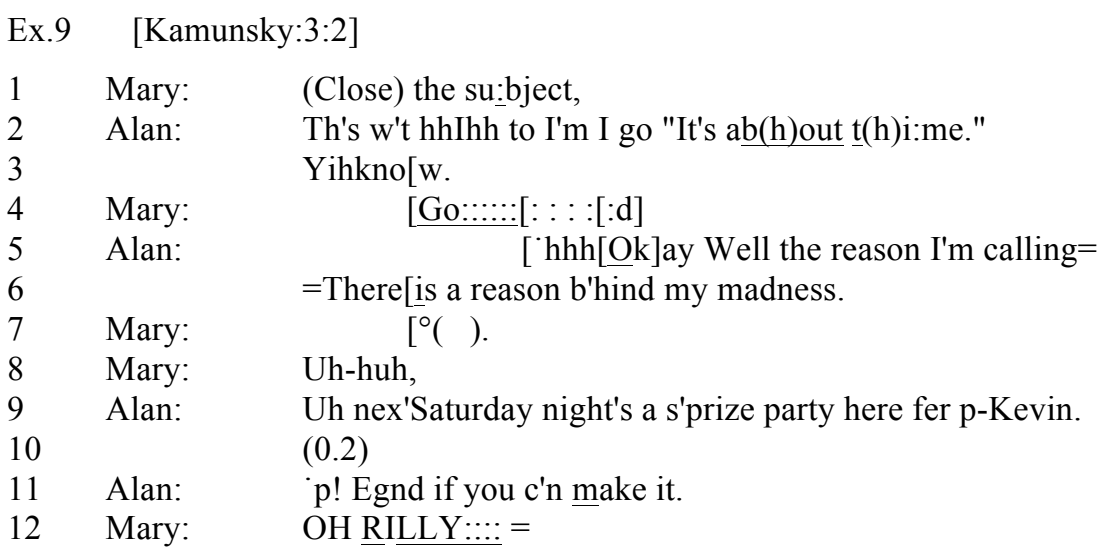

Alan has called Mary, who as soon as she recognised his voice and has been asked How's school, opens with an announcement of her own (Oh alright, guess what happened yesterday) concerning some gossip about mutual friends. So that although as the caller Alan thereby (normatively) has rights to the first topic, Mary has preempted that first topic position. At the point when that topic closes (line 1 in this excerpt), Alan introduces the reason I'm calling (lines 5-6) in what is a displaced 'first position', which is to announce a 'surprise birthday party' for a mutual friend (line 9) to which she is invited (we'll return later to the precise way in which the invitation is formed in line 11). With his prefatory "Okkay" (beginning of line 5) Alan detaches the upcoming turn announcing his reason for calling from what they have been talking about; it is thereby represented as a new topic. So this is pretty clearly designed as his reason for calling, and not connected to prior talk.

It is important to disentangle the 'reason for calling' to invite the other, from the construction of an invitation independently of prior talk/sequential environment. These may be overtly interwoven, as they are in ex.9. But in this next example the imputation that Gordon has called his ex-girlfriend Dana in order to ask whether she'd 
like to get together is unwarranted, analytically. They have been talking for some time when Gordon interrupts their conversation to tell Dana that his friend Norm has arrived to take him out for the evening; time is now limited, so before ending the call Gordon announces that he'll be leaving on the twenty seventh (for the new university term).

\section{Ex.10 [Holt:SO88:1:3:3]}

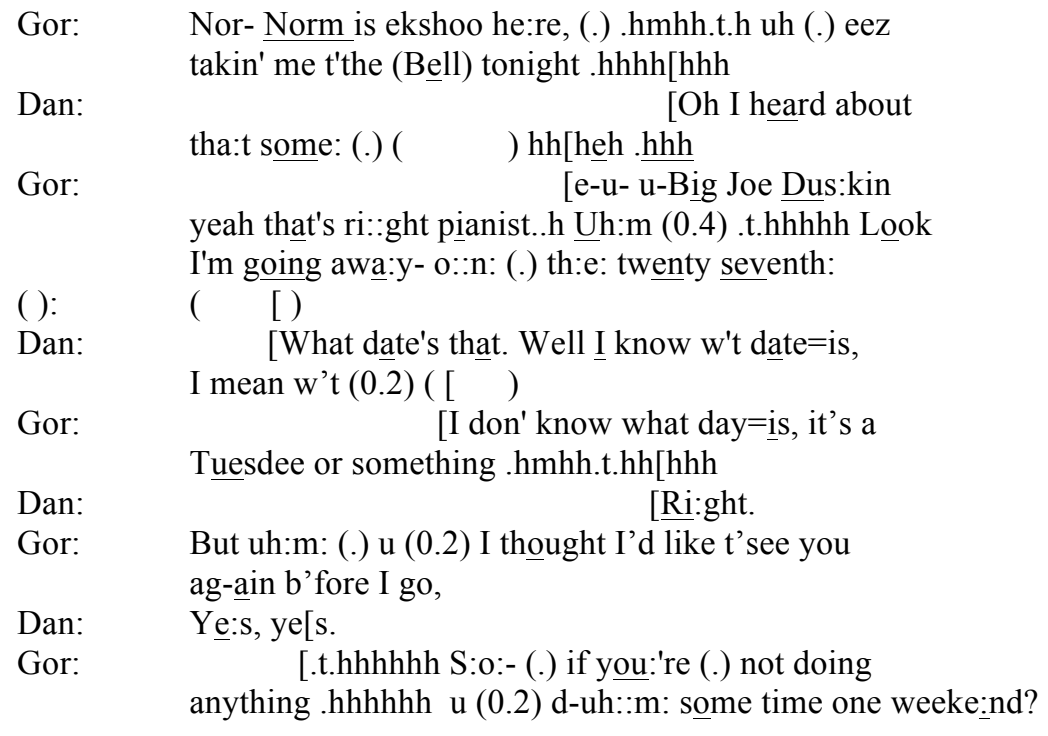

His announcement that he's going away on (line 7) leads into his invitation to her for sometime one weekend (lines 17-18), again designed, through his Look-prefaced announcement, in such a way as to detach it from their previous talk (line 6). It is entirely possible that Gordon has called for this purpose, and makes his invitation at this last opportunity. But that cannot be known, and is quite distinct from his constructing the invitation to be sequentially disconnected from their previous talk, with his [announcement alert Look]+[announcement].

Examples 9 and 10 contrast with cases in which an invitation is designed as having been occasioned by or directly responsive to something that has happened to be said in the immediately prior talk, such as happens in the following. Leslie and Joan are commiserating with one another about the effects on their family's finances of a general economic downturn in the UK. Joan's family is especially affected by the news that her husband will not receive a Christmas bonus this year, so that they are having to really tighten our belts (no holiday next year, no Christmas tree this), to which Leslie, having previously agreed that We're all in the same boat this year, 
replied So are we. Leslie has mentioned another family she knows who are having a difficult time financially (ex.11 lines 1-2).

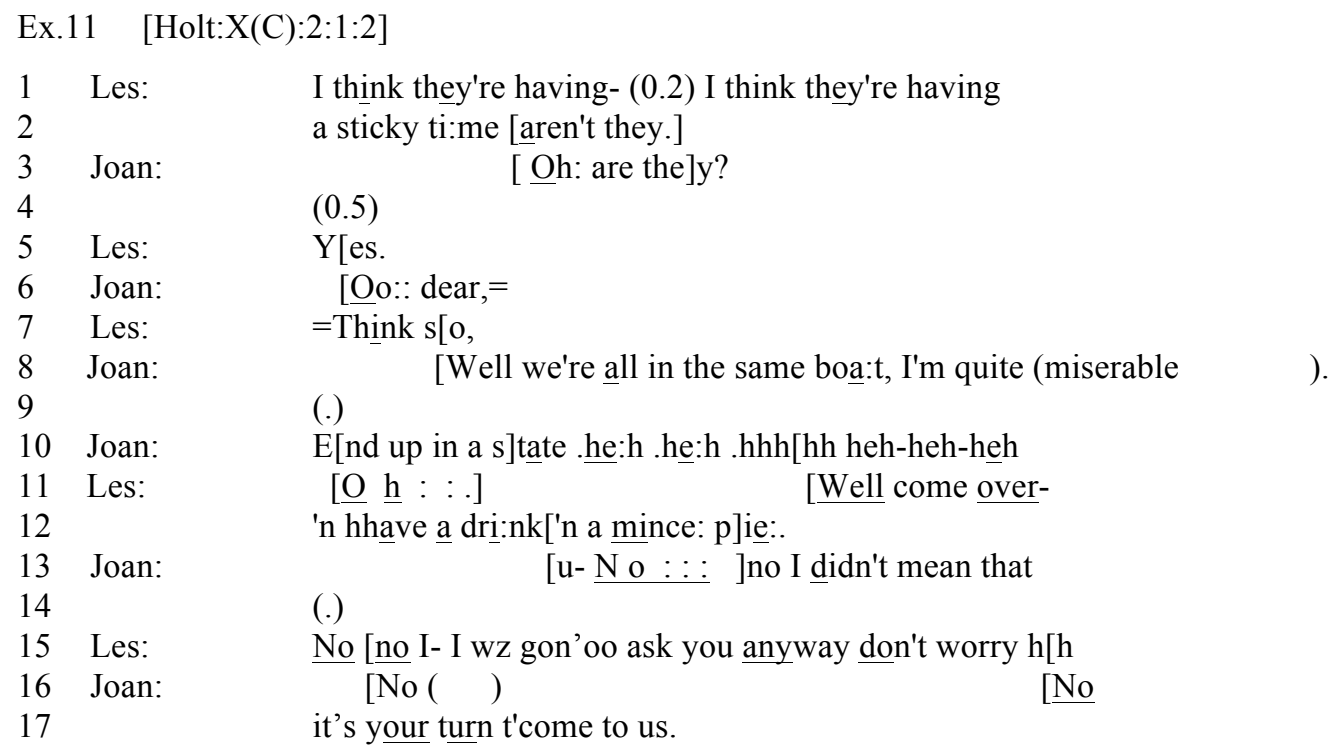

Joan's summary idiomatic response (Drew and Holt 1998) is to repeat we're all in the same boat (line 8), adding an account of her troubled emotional state. That account is constructed from two components, miserable (and more that cannot be heard) and end up in a state; Leslie overlaps the beginning of that second component with "Oh::", which after some delay she continues with "Well". Heritage comments that "Wellprefacing is commonly associated with 'my side' responses to descriptions and evaluations in which the speaker's perspective, while frequently corroborative or supportive, becomes a new point of departure for subsequent talk" (Heritage 2015: 101) (for an instance in which the same pattern of overlap of $O h$ with a first component, then the delayed continuation with well occurs, see Heritage 2015, ex. 25). Which is precisely what happens in this excerpt Leslie's invitation Oh well come over and have a drink and a mince pie is simultaneously a supportive response and a departure from the (topic of) the expense of Christmas hospitality. It is evident that each explicitly treats that invitation as having been generated by Joan's troubled emotional account, each using a double negative No no, Joan to disclaim that she had meant that they were that hard up, and Leslie to claim that she was only taking this as an opportunity, and that she had been going to ask her anyway. 
Here is another example in which an invitation emerges from some immediately prior talk; Emma has called Margy in part to thank her for a luncheon party Margy gave about a week ago.

\section{Ex.12 [NBVII: Power Tools]}

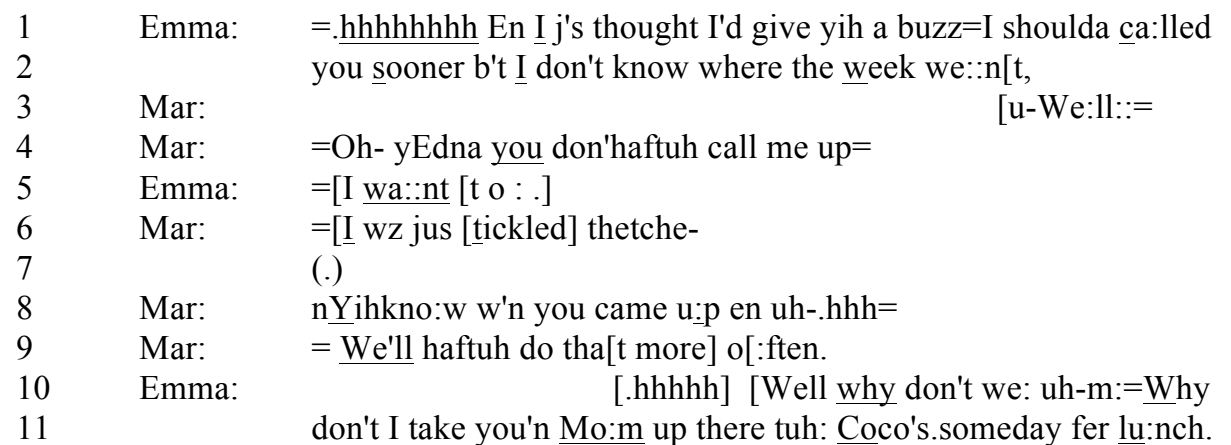

Margy adds to her reassurance that it wasn't necessary for Edna to call to thank her (lines 4, $6 \& 8$ ), the 'encouragement' that they should 'do that' more often (line 9). To which Edna responds in a way that is consistent with normative standards of reciprocity, by inviting Margy (and her mother-in-law, who it was established earlier in the call will be staying with Margy's family in the near future) for lunch at Coco's. There are good ethnographic grounds for knowing that when she says "take you'n Mo:m up there tuh: Coco's" Emma is not offering to give Margy a ride - Edna doesn't drive; so this is not an offer (to drive them up) but an invitation to buy them all lunch. We will consider the ambivalence in Emma's invitation in a later section; for now the observation is the way in which Emma's invitation is produced as a response to their prior talk, especially Margy's contiguous encouragement in line 9 with which she (Emma) affiliates (Sacks 1985). Edna prefaces her turn/invitation in line 10 with $\mathrm{Well}$, in just the way that Leslie did in line 11 of the previous example, denoting again a my-side response that corroborates and supports the prior speaker but is a 'new point of departure'.

The invitation in ex.9, therefore, is constructed to disconnect from their prior talk, to have been independent of anything they had said previously, and indeed to be the reason Alan called. In ex.11 by contrast, Leslie's invitation is constructed and understood to be immediately responsive to Joan's expression of distress; and in ex.12 Emma's invitation is likewise immediately responsive to - and thereby emerges from - Margy's prior remark encouraging their getting together 'more often'. Whatever the 
speakers may have had in mind - and it will be noticed that Leslie indicates/claims that she had been 'going to ask' Joan (line 15) - there is a spontaneity about the design and delivery of the invitations in these latter examples insofar as they are responses to what the other, the invitation recipient, has just said and done in their prior turn. On occasions, however, the other's 'prior turn' in response to which invitations are made arise from and are themselves responses to a prior turn by the one who subsequently invites the other.

\section{Ex.13 [JGII(b):8:14]}
So who'r the boyfriends for the week.

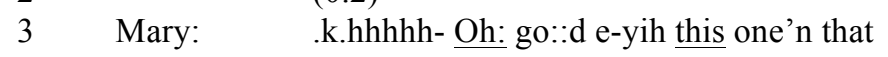
4 one yihknow, I jist, yihknow keep busy en
$5 \quad$ go out when I wanna go out John it's nothing
6 .hhh I don' have anybody serious on the string,
7 John: $\quad$ So in other words you'd go out if I:: askedche
$8 \quad$ out one a' these times.
9 Mary: $\quad$ Yeah! Why not.

$\begin{array}{lll}1 & \text { John: } & \text { So wh } \\ 2 & & (0.2)\end{array}$

John's enquiry in line 1 is one of those class of actions termed pre-sequences, here specifically a pre-invitation (Schegloff 2007:28-57, and for pre-invitations 289-34); whether or not his enquiry in line 1 was made in the service of the subsequent invitation that he 'intended' to make, his invitation in lines $7 \& 8$ is constructed as directly responsive to, indeed a formulation of, Mary's prior account of her current love-life (So in other words ...). Something similar is evident in this next example in which Emma's invitation (lines $13 \& 15$ ) is made when, having been asked what she is doing (line 1), Nancy responds with an account implying that she would rather not be doing what she is doing (lines 5 \& 7-9) (for an analysis see Drew 2005).

Ex.14 [NB:II:2:22]

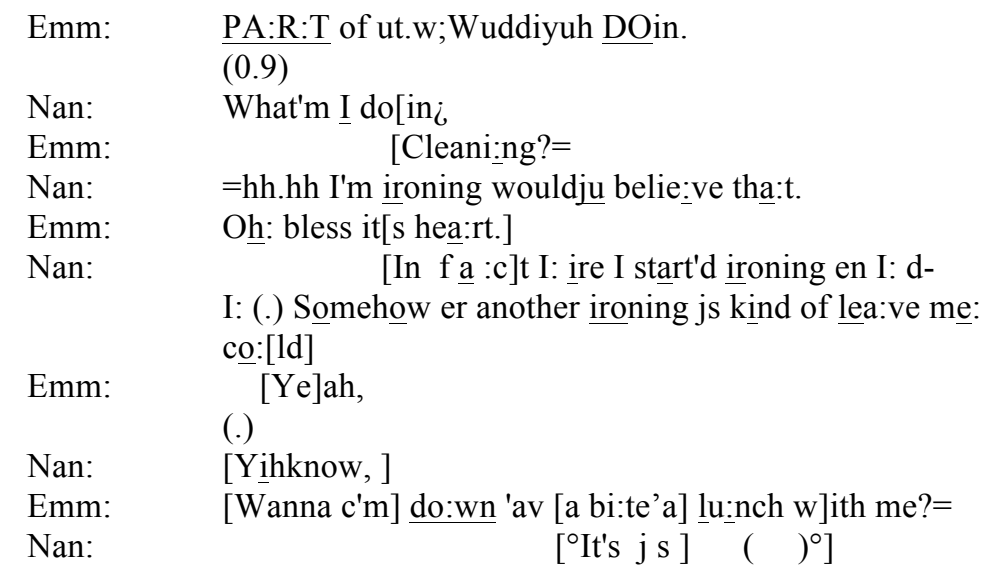


Emma's invitation in line 13 is designed to be connected and responsive to Nancy's report, in part through its sheer placement, its 'nextness', but in part also through the contracted form "Wanna", through which her invitation is constructed as being casual, as close to being an offer or a suggestion, as though to relieve Nancy of her domestic chores.

There are then some linguistic designs, including grammatical forms, through which invitations are constructed as 'firsts', as initial actions unconnected with prior talk, as in exs.9 \& 10; and others through which invitations are constructed as 'nexts', as directly responsive to and connected with the prior speaker's turn. These designs cannot be taken as indicators that 'in fact' a speaker's intention - before the interaction - had or had not been to invite the other, nor that the 'reason for calling' was or was not to invite the other. They may be, but are not necessarily (e.g. ex.10) constructed as having been the reason for calling, or constructed as a response to what the other said. What a speaker's 'actual' intentions might have actually been are not to be known (Melden 1961), and are not in point here. However, we find what might be regarded a hybrids, in which the position and sequential management of the invitation indicates that the speaker is responding to the other's talk; but in which the construction of the turn in which the invitation is made indicates that the invitation is independent of the other's prior turn. In this following example Geri and Shirley, who are friends and students, though attending different universities, have been discussing among others things how much more of the semester is left, about which they have disagreed. The extract begins when they have figured out how they came to think differently about how many weeks remain.

\section{Ex.15 [TC:I:I Geri-Shirley]}

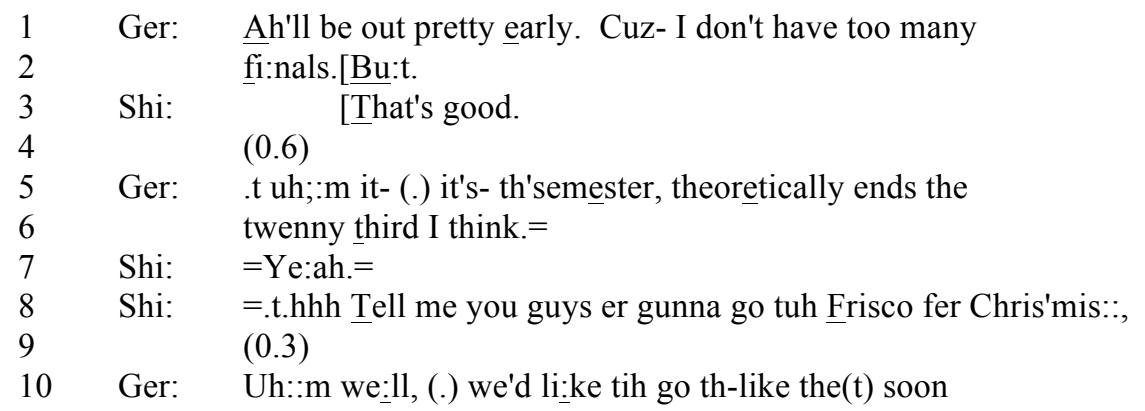




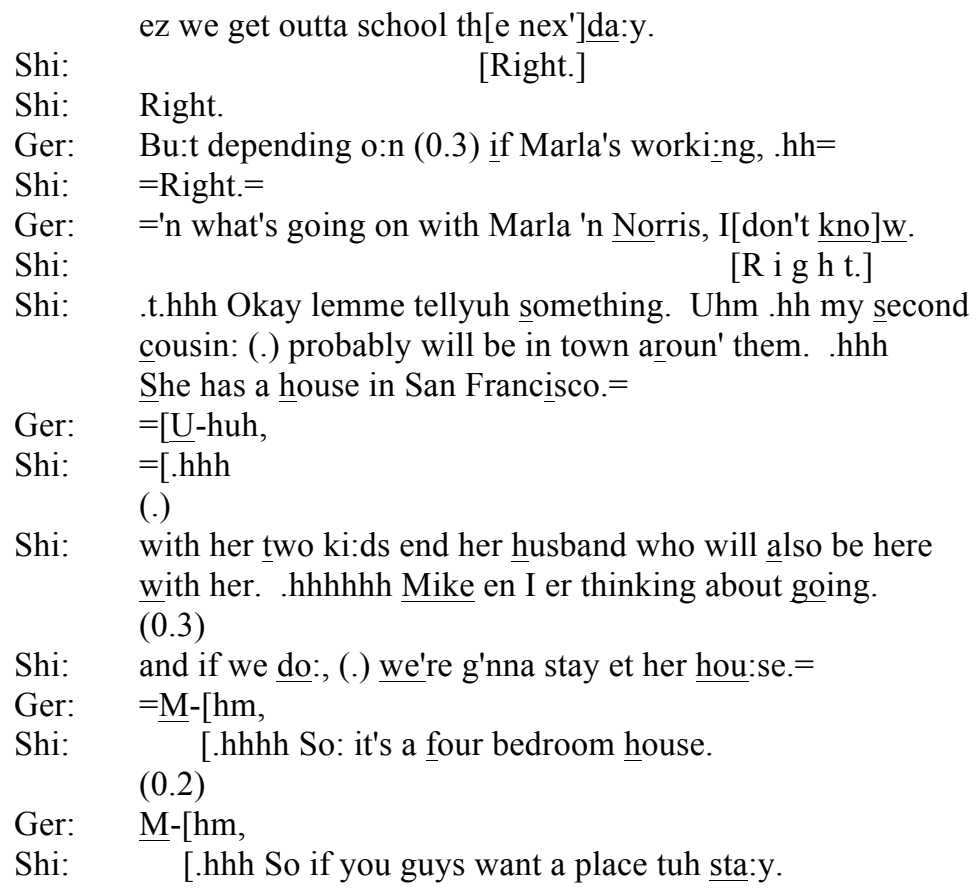

Shirley asks Geri about her plans immediately the semester finishes on the $23^{\text {rd }}$ (lines 6-8), “Tell me you guys er gunna go tuh Frisco fer Chris'mis::,", in a declarative construction embedded in imperative mood, Tell me. Geri indicates that her preference would be to leave for San Francisco the next day (lines 10-11) (though there are some contingencies), to which Shirley responds with a sequence-opening announcement, "Okay lemme tellyuh something" (line 18). Recalling the announcement format of the preface to Alan's invitation in ex.9, here too in ex.15 Shirley brings this announcement sequence to a close with an invitation in line 32 . The conditional format of her invitation "So if you guys want a place tuh sta:y.", parallels that of Alan's in ex.9 "Egnd if you c'n make it.". The ambivalence evident in the incompleteness of each of their invitations will be considered later. What is so striking here is the construction of each through the linguistic forms of 'announcing' conveys the independence of the invitation to be delivered; although in the latter case, ex.15, the placement of Shirley's imperatively formatted enquiry in line 8 connects it with the date the semester ends (lines 5, $6 \& 8$ ).

\section{The kind of occasion represented through invitation design}

We have been considering the associations between variations in the linguistic forms through which invitations are delivered, and the sequential and interactional circumstances (environment) in which they are delivered. Broadly speaking, these 
forms divide according to their displaying an independence from prior talk, and those that manifest their connection with prior talk. This broad distinction roughly maps onto a distinction between the kinds of occasions that are represented in the invitation; namely a distinction between a pre-arranged occasion to which the recipient is being invited to join (e.g. as one of a number of invitees), and an occasion that will involve just the speaker and the recipient of the invitation. This is a distinction between prearranged events, and events that are arranged spontaneously, that is interactionally generated in the talk.

Recall that Alan's invitation in ex.9 concerns a surprise birthday party for a mutual friend of theirs.

[From ex.9]

9 Alan: Uh nex'Saturday night's a s'prize party here fer p-Kevin.

$10 \quad(0.2)$

11 Alan: $\quad$ p! Egnd if you c'n make it.

The prefatory account of the birthday party together with the conditional form of the invitation indicate clearly that the party has been arranged, and that Mary is being invited to join the occasion. Something similar is evident in ex.15 in Shirley's report that she and Mike are thinking of going, that if they do they'll stay at her cousin's house, and if they do then Geri is invited. So again Geri is invited to 'join'. That too happens in ex.16.

Ex.16 [TC1(a):14:2]

Alb: Uhhhhhh. So you guys comin over tihni:ght?

Ben: Yeah.

$(0.2)$

Alb: Yi'are.hh

Ben: Yah.

Alb: $\quad$ Okay. Good.We're havin a h-buncha people over too[:

Ben: [Oh are yih?

(.)

Alb: Yeh it sort'v uhhh[stardih-]started out ez sorta impromptu= [((door) $)]$

Alb: =en now it's, ended up tih be a party,

Ben: Oh yeaah? 
By prefacing his invitation in line 1 So, and not asking for instance whether Ben would like to come over tonight, Albie hints at an event that has already been arranged, which is confirmed in his announcement (line 6) and subsequent account for how the event has happened (lines $9 \& 11$ ). (In his response in line 7 Ben treats the announcement of the party as news, though there is evidence that he's heard about the 'party' to watch a game on TV and have some beers, and has called Albie perhaps with the aim of being asked.) In cases such as these, then, the event, the party whatever, is prearranged and will happen independently of whether this invitee can make it.

In those invitations formed as interactionally generated from the prior talk, however, the occasion is constituted through the invitation; it comes into being through the designedly spontaneous invitation to come over for lunch,

\section{[from ex.14]}

13 Emm: [Wanna c'm] do:wn 'av [a bi:te'a] lu:nch w]ith me?=

14 Nan: $\quad\left[{ }^{\circ} I^{\prime}\right.$ s j s ] ()$\left.^{\circ}\right]$

15 Emm: =Ah gut s'm beer'n stu:ff,

to come over for mince pies,

[from ex.11]

10 Joan: $\quad E[$ nd up in a s] tate .he:h .he:h .hhh[hh heh-heh-heh

11 Les: [은.

12 'n hhave a drị:nk['n a mince: p]ie:.:

to be taken for lunch,

[from ex.12]

$9 \quad$ Mar: $\quad=$ We'll haftuh do tha[t more $] \mathrm{o}[:$ ften.

10 Emma: [.hhhhh] [Well why don't we: uh-m:=Why

11 don't I take you'n Mo:m up there tuh: Coco's.someday fer lu: $\underline{\text { nch. }}$

or to go on a date.

[from ex.13] 
$\begin{array}{lll}7 & \text { John: } & \text { So in other words you'd go out if I:: askedche } \\ 8 & & \text { out one a' these times. } \\ 9 & \text { Mary: } & \text { Yeah! Why not. }\end{array}$

The 'designed spontaneity' in each case is achieved through connecting the invitation with the immediately prior talk, largely though not entirely through turn initial components that connect a current turn with its prior. Hence the invitations are designed to be heard as touched off by the other's prior turn(s)/talk.

\section{Equivocal forms}

I mentioned in the Introduction that across the variety of linguistic forms through which invitations are constructed, their designs, or more properly the design of the turns in which invitations are done, have in common that they tend to be equivocal forms/designs ${ }^{\mathrm{i}}$ - equivocal in the sense of something like an uncertainty, a tentativeness in asking, amounting to a kind of cautiousness. I was careful to emphasise that 'equivocal' here does not connote a lack of sincerity; it is perhaps not uncommon that when researching seemingly altruistic actions (perhaps more correctly commissives; Couper-Kuhlen 2014), such as offers, invitations and apologies, it is tempting to begin by attempting to distinguish 'sincere' from 'insincere' occurrences of the action in question. But to be clear, I am not proposing that equivocal forms for inviting are an indication of the inviter's insincerity, indeed far from it. In some cases, a speaker may report some event or occasion or circumstance to another, and thereby elicit from the other a self-invitation (Can I go see it, in response to the prior speaker reporting that we are putting on [a play] on the tenth of December). The speaker has thereby not made an invitation, but has managed the interaction in such a way (through 'reporting') that the other makes the (self-)invitation.

"The official character of reportings, as just telling recipient about some occasion, is oriented to and sustained by the way in which recipients ... straightaway invite themselves, without first waiting to see whether an invitation would be forthcoming. . . . (Recipients thereby) treat their presence/participation as something that the prior speaker would desire. ... So that inviting themselves - and in seeming assured of their probable success $\ldots$ - the recipients are requesting/offering to do things that they can tell from the prior reportings would be welcomed by prior speakers. Hence the reportings . . . can be cautious ways of finding out whether recipients are 
available ... Not knowing the chances of whether the recipient are free/willing to come, speakers can use reportings of a forthcoming or present occasion ... leaving the coparticipation (in the occasion) for the recipient to determine" (Drew 1984:143)

Avoiding making an invitation directly or officially but instead getting the other to make a self-invitation is perhaps an extreme case of equivocation. In the great majority of cases in a sample in which a speaker invites the other (i.e. makes an explicit invitation) in my English corpus, the invitation is made through constructions that are equivocal in design.

The first of these equivocal forms is close to those just mentioned, in which the speaker does not actually or officially make an invitation; in this first equivocal form, the speaker also does not - quite - make an invitation.

\section{Ex.17 [Kamunsky:3:2] (This is an extension of ex. 9 above)}

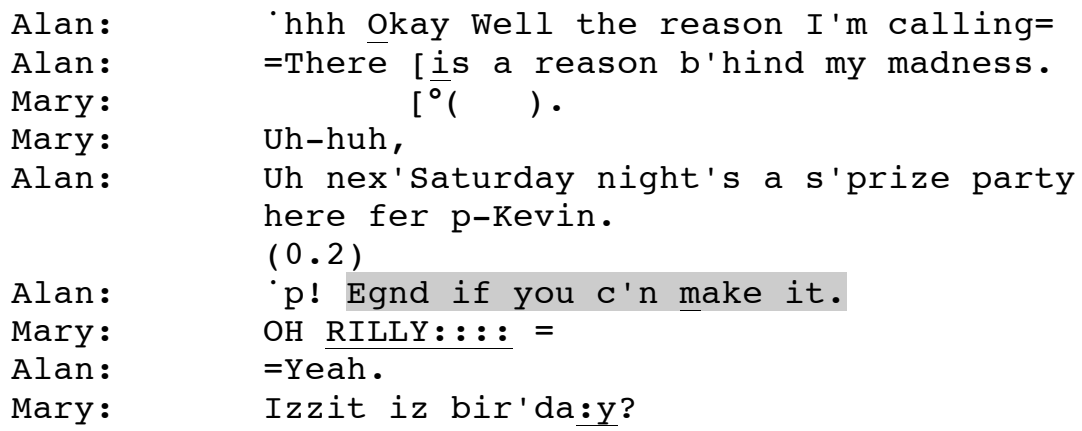

After Alan's news about a surprise party for Kevin (lines 5-6), he invites Mary using a conditional form that is not completed, if you can make it (line 8). This is equivocal in two respects; Alan does not follow his report of the surprise party with a clear modal invitation, e.g. Would you like to come? Neither does he complete the conditional construction with an invitation phrase such as we'd love you to come, or you'd be welcome. An invitation has not quite been made; it is begun but then left hanging, incomplete, unspoken. And in this respect it is noticeable that in response Mary does not 'accept' but rather responds to the news about the surprise party for Kevin (“OH RILLY:::::”, line 9); indeed subsequently Mary does not explicitly or officially accept an invitation. Though it is clear from the subsequent conversation that she is going to go to the party (they discuss details about who is going, how she'll get to the party, what she'll bring in the way of a present and eatables), nevertheless 
there is no turn in which she overtly accepts; an invitation has not been fully and officially made, and so an acceptance is not given.

The following are two further cases of similarly 'incomplete' invitations.

Ex.18 [TC:I:I] (Excerpt from ex.15)

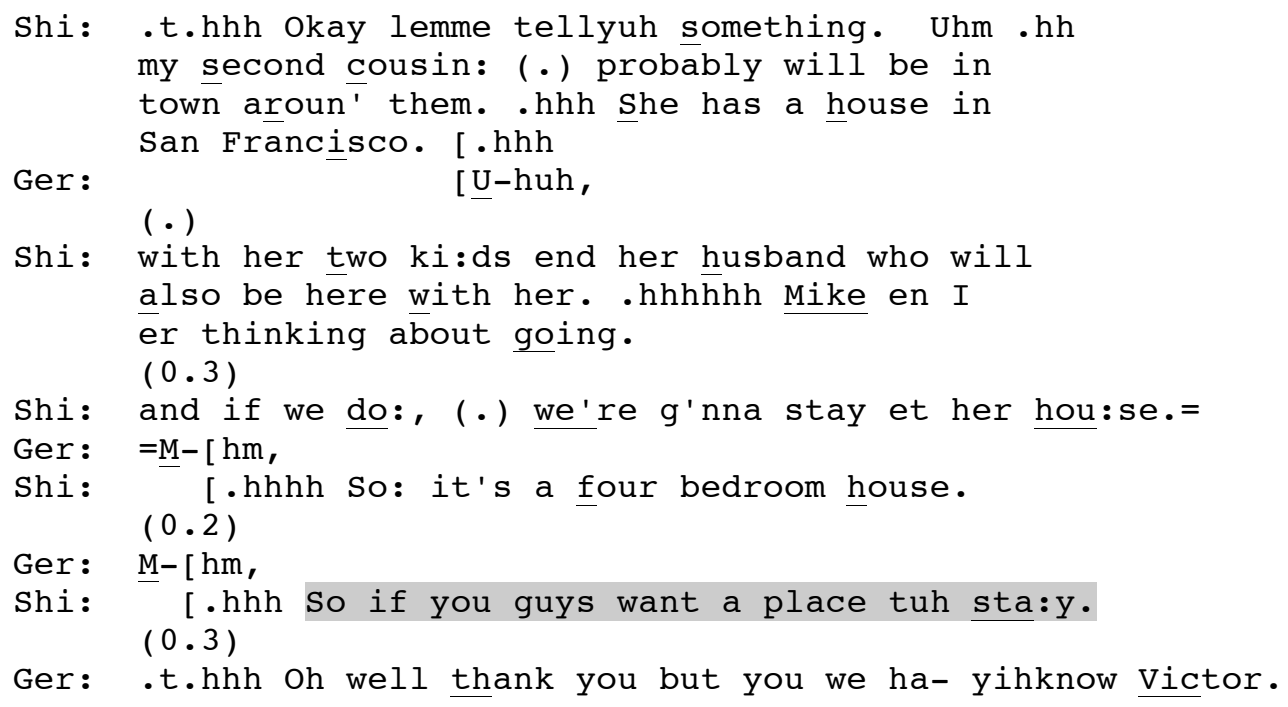

Ex.19 [Holt:SO88:1:3:3] (Excerpt from ex.10)

Gor: $\quad$ Uh:m (0.4) .t.hhhhh Look I'm going awa:y-

o::n: (.) th:e: twenty seventh:

Dan: What date's that. Well $\underline{\underline{I}}$ know w't date $=$ is, I mean w't (0.2) ( [ )

Gor: $\quad$ [I don' know what day=is, it's a

Tuesdee or something .hmhh.t.hh[hhh

Dan: [Ri:ght.

Gor: But uh:m: (.) u (0.2) I thought I'd like t'see you ag-ain b'fore I go,

Dan: Yes:s, ye[s.

Gor: [.t.hhhhhh S:o:- (.) if you:'re (.) not doing anything .hhhhhh u (0.2) d-uh::m: some time one weeke:nd? $(0.4)$

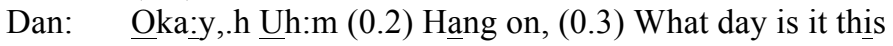
weekend let's think....

In ex.18 Shirley first reports news (let me tell you something), the upshot of which is that she will be staying at and have the run of her cousin's house in San Francisco, which has plenty of room (lines 1-13). Then just as Alan did in line 8 of ex.17, Shirley makes a 'sort of' invitation using a conditional form (if you guys), an invitation that is left incomplete. Likewise in ex.19 Gordon reports the news of some circumstance, that he will be leaving (for the new university term) shortly and that he 
would like to see Dana before he leaves; after which he makes a 'sometime' invitation (if you're not doing anything, lines 12-13), the hazards of which might be bound up with their relationship having ended some time before this, though they still 'keep in touch'. Each of these incomplete not-quite-invitations in exs. 18 and 19 is prefaced with so (see also examples 2/16, 8/13, and 15 above), which Bolden demonstrates is an other-attentive marker of 'emergence from incipiency' that can launch an action trajectory, as so does for the invitations here (Bolden 2006).

What is beginning to be evident is that speakers tend not to use variously 'assertive' forms - for instance constructions employing imperative or modal forms (Come over) (Couper-Kuhlen 2014, 636-641) - when making invitations. Instead they use constructions that embed indications of anticipated difficulty or possible ambivalence on the part of the recipient. This is apparent, for instance, in these negative forms of the invitation

Ex.20 [NBVII Power Tools] (Extended version of ex.12) (Edna has called to thank Margy for a lunch party. There are good ethnographic grounds for knowing that Edna isn't offering to give Margy a ride - Edna doesn't drive)

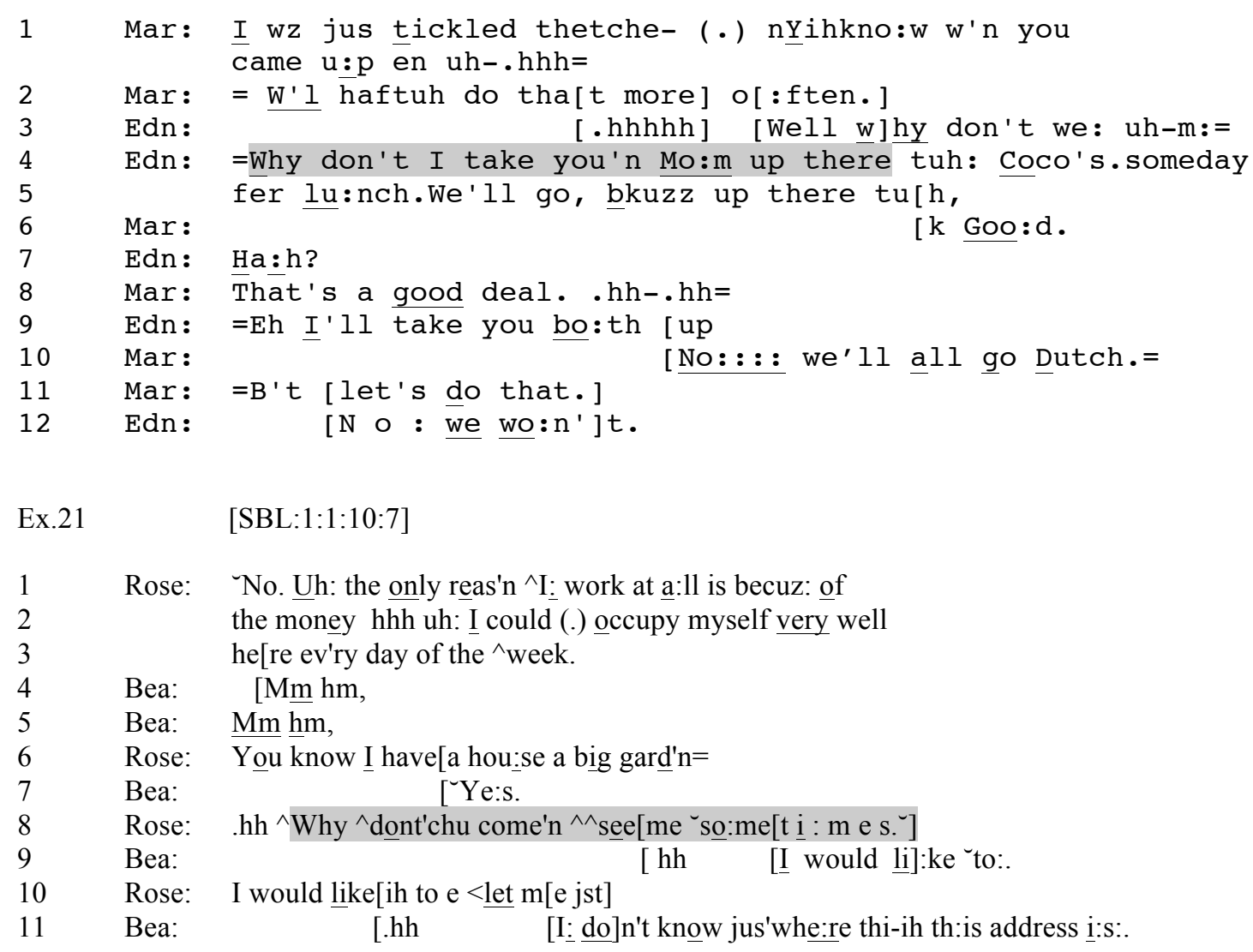


In each of these examples Edna and Rose, respectively, might have used 'direct' forms such as I'll take you n'mom . . . or I'd like to take you n'mom in ex.20, or Come and see me . . in ex.21. Edna's equivocation in ex.20 is apparent in her having started with what was going to be a suggestion or proposal to go together, "Well why don't we: (have lunch etc.)", which she then changes to make it an invitation (Drew 2006; see also Couper-Kuhlen 2014, 642.). Moreover, the turn is prefaced with Well, which as was noted earlier commonly functions as a 'my side' alert to a turn or action that is "not straightforward" (Heritage 2015; see also Schegloff \& Lerner 2009). The transition from a proposal-format to one inviting the other is perhaps equivocal regarding 'whose agentivity?' (Couper-Kuhlen 2014, 627).

Finally, negatively formed constructions are often used in sequential environments in which there is a trouble of some kind, such as when a previous attempt ran into trouble; or in which speaker has grounds for anticipating that the invitation may run into trouble (Drew 2013b). Rose's use of a negative construction Why don't you . . in ex.21 is similarly poised to encounter difficulty. Mary and Rose know each other but not well; it's not clear whether they have met, but it is clear that Bea has not been to Rose's house (line 11), so they are not on visiting terms. Moreover Bea has called Rose on business; they are both nurses, Bea is trying to find a replacement for herself and has offered the position to Rose who has turned it down (I'm sorry to have to say no), after which they consider other mutual acquaintances who might be suitable. The sequential environment is therefore hazardous, which is reflected in the negative construction of Rose's invitation.

It will be recalled that Alan's uncompleted invitation in ex.17 (and if you can make it, line 8), Shirley's in ex.18 (so if you guys want a place to stay, line 16), and Gordon's in ex. 19 (if you're not doing anything, line 12) are conditionally formed invitation turns. So too is the invitation that Rose makes a little later after Bea has accepted her invitation in ex.21 (line 9). In response to Bea's acknowledgement that she does not know where Rose's house is (line 11), Rose gives her directions about how to find the address/her house (65 lines omitted). As soon as they have established precisely where Rose lives, and Bea is satisfied that she can easily get there (That isn't far at all), Rose invites Bea again to visit, or rather reissues her earlier invitation, but this time specifically for this morning (lines 1-2); her first version of the invitation in 
ex.21, line 8 , had been a generalised 'sometimes' invitation, which again is cautious or equivocal (see also Gordon's in ex.19, sometime one weekend).

Ex.22 [SBL:1:1:10:8]

\begin{tabular}{|c|c|c|}
\hline $\begin{array}{l}1 \\
2\end{array}$ & Rose: & $\begin{array}{l}\text { And uh the: if you'd care tuh come over, en } \\
\text { vis^it u little while this morn^ing I'll }\end{array}$ \\
\hline 3 & & give you $\left[\right.$ cup $\mathrm{a}^{\prime \wedge} \mathrm{coff}$ ee. \\
\hline 4 & Bea: & {$[\mathrm{khhh}-1+-$} \\
\hline 5 & Bea: & Uhhh-huh hh W'l thet's awf'lly sweet of yuh \\
\hline 6 & & $\mathrm{I}^{\wedge} \mathrm{don}^{\prime} \mathrm{t}$ think I c'n make it this morning, \\
\hline 7 & & hheeuhh uh:m $(0.3)$ 'tch I'm running en a:d \\
\hline 8 & & in the paper 'nd an:d uh hh I haftih stay \\
\hline 9 & & near the pho::ne, \\
\hline 10 & Rose: & $(\mathrm{Ya}[\mathrm{h})$ \\
\hline 11 & Bea: & [.hhhh \\
\hline 12 & Rose: & Alright? $=$ \\
\hline 13 & Bea: & $=. \mathrm{hh} \mathrm{A}[\mathrm{nd}$ \\
\hline 14 & Rose: & {$\left[\right.$ Well eh ${ }^{\wedge}$ sometime when you ${ }^{\wedge}$ are free, $\mathrm{h}$} \\
\hline 15 & & give $\wedge^{\prime}$ a call becuz ah'm not alwiz ho:me. \\
\hline 16 & Bea: & $\mathrm{Mm} \mathrm{hm}$ \\
\hline 17 & Rose: & $\mathrm{hh} \overline{\mathrm{h}} \mathrm{h}$ \\
\hline 18 & Bea: & [Why I'd like ^to en thanks a lo::t. \\
\hline 19 & Rose: & An' I'd love ${ }^{\wedge}$ tih have you: visit, \\
\hline
\end{tabular}

The grammatical format with which Rose invites Bea for 'this morning' is a conditionally formed construction, if you'd care to come over (line 1). The apparent caution of the conditional construction, reminiscent of the low entitlement associated with such forms when used in requesting (Curl and Drew 2008), seems to orient to the 'hazards' of inviting someone whom one does not know well, who has called on business (i.e. the one making the invitation is not the caller but the called, cf. Alan in ex.17 line 1) and hence transitioning from business to social, for the same day and presumably in only an hour or two's time. The potential this has to run into trouble is confirmed in Bea's response declining, for this occasion at least (lines 5-9).

The principal features of the design of turns in which invitations are being made are 'incomplete' constructions, conditional forms, and negative framed interrogatives all of which are equivocal constructions. These are the features that are most frequent in the sample of invitations assembled for this study. However, there is a miscellany of other constructions that are likewise equivocal formats; an example shown earlier (e.x13) will have to suffice to illustrate these other less frequent formats.

Ex.13 [JGII(b):8:14]

1 John: So who'r the boyfriends for the week. 


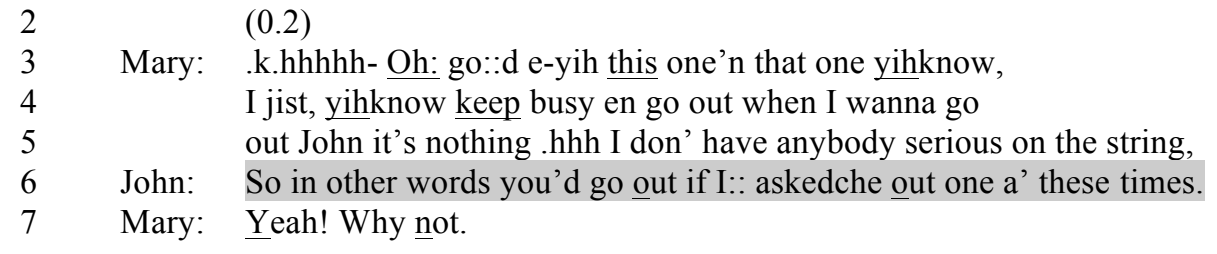

John and Mary are middle-aged, John is married, and he and Mary have what appears from this call to be an 'occasional' relationship. When he receives what seems to be an encouraging reply to his pre-sequence enquiry, John designs his invitation in such a way as to embed a conditional form (if I asked you out, line 6) in a turn constructed as an upshot (So) arising from a formulation (in other words) (Heritage 1985) of Mary's response to his enquiry. In addition to which, the invitation is not specific as regards time or occasion, but is generalised or open (one of these times). The design of John's invitation in line 6 combines features associated with equivocation evident in previous examples (conditional forms, non-time specific) with a format that represents his invitation as arising from and perhaps encouraged or 'permitted by' Mary's account of her social life. The hazards of making an invitation of this kind, in these circumstances, and which are reflected in the thoroughly equivocal design of John's invitation, hardly need to be explained here.

\section{Conclusion}

It is becoming clear that some, perhaps many, of the social actions or activities that might be regarded as 'speech acts' are, when considered in their spatial and embodied contexts in face-to-face interaction, conducted variously through a combination of speech (spoken language) and non-vocal conduct, or even entirely through non-vocal conduct. So for instance requesting may be done through talk alone, or through the coordination of speech and non-vocal conduct (Rossi 2014; for a general review see Drew and Couper-Kuhlen 2014); indeed when one considers closely how people manage to recruit the assistance of others or come to give assistance, speech act terms such as 'requests' and 'offers' seems less apposite than regarding the embodied process of giving assistance as 'recruitment' (Drew and Couper-Kuhlen 2014, Kendrick and Drew 2016). All the examples in this analysis are taken from telephone conversations, so no account is taken here of how invitations may be conducted in face-to-face interactions. Nevertheless, it is likely that, along with apologies, 
invitations can only be conducted or completed through an explicit verbal act, an utterance in which an invitation (including self-invitation) is delivered (see Robinson 2004 on explicit apologies). Certainly in all the examples in my sample and all those considered here, a speaker makes an explicit invitation in an identifiable turn-at-talk (albeit in some cases an 'incomplete' invitation). The focus in this analysis has been on the design or construction of the turns in which invitations are made explicitly. To begin with, I have shown that variations or differences in the form or construction of invitations are associated with two intersecting contingencies, namely the interactional circumstances in which an invitation is made - specifically whether the invitation is touched off by or in some fashion designed as responsive to something said during the interaction; or whether the one making the invitation initiated the conversation, in part at least, in order to invite the other (e.g. the reason I'm calling in ex. 9/17). The second contingency reflected in the design of the invitation turn is the kind of occasion represented in the invitation.

However, across the variations in turn design associated with these interconnected contingencies there is one feature of the (grammatical) design/construction of the turns in which great majority of the invitations in the sample are made explicitly which is that the formats are almost all 'equivocal'. That equivocality is evident in a range of construction formats, including 'incomplete' invitations, negative constructions and conditional constructions; moreover the local circumstances of equivocation are divers. But across the range of grammatical forms, constructions and construction types, it is clearly the case that invitations are rarely delivered in what might be regarded as 'assertive' formats such as imperatives or modal forms. An exception is ex. 11 above, when in line 11 Leslie invites Joan for a drink and mince pies at Christmas in the imperative mood, Well come over . . . .

\section{[From ex. 11]}

\begin{tabular}{|c|c|}
\hline Joan: & $\begin{array}{l}\text { Well we're all in the same boa:t, I'm quite (miserable } \\
\text { (.) }\end{array}$ \\
\hline Joan: & $\mathrm{E}[\mathrm{nd}$ up in a s] tate. he:h. he:h. $\mathrm{hhh}[\mathrm{hh}$ heh-heh-heh \\
\hline Les: & {$[\underline{\mathrm{O}} \underline{\mathrm{h}}::{ }] \quad[$ Well come over- } \\
\hline
\end{tabular}

Even here the invitation is well-prefaced, which as we have seen above commonly functions to alert the recipient to a turn or action that is "not straightforward". 
Moreover this is the only such case that occurs in my sample. So for the most part invitations are made in such a way as to be equivocal, though whether on behalf of the one making the invitation or the one receiving it is not necessarily possible to say and would only be speculative. However, it is evident from this feature of the format of invitations that speakers are orienting to the hazards of making an invitation, whatever those hazards might variously be - though it seems as though the anticipated hazards go beyond that of whether the recipient is likely to be able to accept, which is the hazard for which pre-invitations may be mobilised.

\section{$\underline{\text { References }}$}

Bolden, G. (2006) Little words that matter: Discourse markers 'so' and 'oh' and the doing of other attentiveness in social interaction. Journal of Communication, 56: 661688.

Couper-Kuhlen, E. (2014) What does grammar tells us about action? Pragmatics, 24: 623-647.

Curl, Traci (2006) Offers of assistance: constraints on syntactic design. Journal of Pragmatics. 38: 1257-1280.

Curl, T. and Drew, P. (2008) Contingency and action: a comparison of two forms of requesting. Research on Language and Social Interaction, 41, 2008:1-25.

Drew, P. (1984) Speakers' 'reportings' in invitation sequences. In Atkinson, J.M. and Heritage, J. (eds.) Structures of Social Action: Studies in Conversation Analysis. Cambridge, Cambridge University Press: 129-151.

Drew, P. (2005) Conversation analysis. In Fitch, K. and Sanders, R. (eds.) Handbook of Language and Social Interaction, Lawrence Erlbaum: 71-102. 
Drew, P. (2013a) Turn design. In T.Stivers and J.Sidnell (eds.) Handbook of Conversation Analysis. Blackwell:131-149.

Drew, P. (2013b) Conversation analysis and social action. Journal of Foreign Languages (Shanghai, PR China), 37: 2-20.

Drew,P. and Holt,E. (1998) Figures of speech: figurative expressions and the management of topic transition in conversation. Language in Society, 27: 495-523

Drew, P. and Couper-Kuhlen, E. (2014) Requesting - from speech act to recruitment. In P.Drew and E.Couper-Kuhlen (Eds.) Requesting in Social Interaction, Amsterdam, Benjamins: 1-34.

Glenn, P. (2003) Laughter in Interaction. Cambridge University Press.

Heritage, J. (1985) Analyzing news interviews: aspects of the production of talk for an overhearing audience. In T. van Dijk (Ed.) Handbook of Discourse Analysis, Vol.3 (Discourse and Dialogue), London, Academic Press: 95-117.

Heritage, J. (2015) Well-prefaced turns in English conversation: a conversation analytic perspective. Journal of Pragmatics, 88: 88-104.

Heritage, J. and Raymond, C. (2015) Are explicit apologies proportional to the offenses they address? Discourse Processes, 53: 5-25.

Holt, E.J. (2013) “There's many a true word said in jest”: seriousness and nonseriousness in interaction. In P.Glenn and E.Holt (eds.) Studies in Laughter in Interaction. London, Bloomsbury: 69-89.

Isaacs, E.A. and Clark, H.H. (1990) Ostensible invitations. Language in Society, 19: 493-509.

Kendrick, K. \& Drew, P. (2016) Recruitment: offers, requests, and the organization of assistance in interaction. Research on Language and Social Interaction, 49: 1-19. 
Robinson, J. (2004) The sequential organization of 'explicit' apologies in naturally occurring English. Research on Language \& Social Interaction, 37:291-330.

Rossi, G. (2014)When do people not use language to make requests? In P.Drew and E.Couper-Kuhlen (Eds.) Requesting in Social Interaction, Amsterdam, Benjamins: 303-334.

Sacks, H. (1987) On the preferences for agreement and contiguity in sequences in conversation. In G.Button and J.R.E.Lee (Eds.) Talk and Social Organisation. Clevedon, Multilingual Matters: 54-69.

Sacks, H. (1991) Lectures on Conversation (Volume 2). Oxford, Blackwell.

Schegloff, E.A. (2007) Sequence Organization in Interaction: A Primer in Conversation Analysis. Cambridge, Cambridge University Press.

Schegloff, E.A. \& Lerner, G. (2009) Beginning to respond: Well-prefaced responses to wh-questions. Research on Language and Social Interaction, 42: 91-115.

\footnotetext{
${ }^{\mathrm{i}}$ I have borrowed this term from Holt, from her account of the property of laughter, to indicate the non-seriousness of what's being said and thereby to detoxify what - if it were understood to be serious - might be disaffiliative, insulting and the like. Holt specifically refers to 'turns designed to be equivocal' (Holt 2013). Furthermore Glen has noticed the ambivalence conveyed through laughter when making offers, invitations and the like (Glenn 2003, chapter 6, especially pp.135-137); but since I have not found any cases in my sample of invitations accompanied by laughter, I have not explored this form of equivocality in inviting.
} 